\title{
Estimativa da oferta de biomassa florestal em povoamentos de Pinus taeda L. após intervenções culturais
}

\author{
Estimation of the offer of forest biomass in populations of Pinus taeda L. after \\ cultural interventions
}

\section{Juliana Ceccato Ferreira', Thielly Schmidt Furtado Stähelin'II, Márcia Silva de Jesus ${ }^{\mathrm{III}}$, Graciela Inês Bolzon de Muñiz ${ }^{\mathrm{IV}}$, Martha Andreia Brand", Thaís Pereira Freitas ${ }^{\mathrm{VI}}$}

\begin{abstract}
Resumo
Com a determinação do quanto de biomassa florestal é gerada após as intervenções culturais é possível definir as áreas passíveis de exploração. Com isso, o objetivo do trabalho foi quantificar e estimar a oferta de biomassa de Pinus taeda L. disponível após as intervenções culturais. O experimento foi realizado em reflorestamentos nos municípios dos estados do Paraná e Santa Catarina, com idades de 3 anos (primeira desrama), 5 anos (segunda desrama), 7 anos (terceira desrama), 11 anos (primeiro desbaste) 19 anos (segundo desbaste), 23 e 33 anos (cortes rasos). Para cada idade foram amostradas 10 árvores e quantificados os componentes acículas, galhos, ponteira e casca. Após o corte raso, aos 23 anos houve maior disponibilidade de biomassa individual $\left(372,6 \mathrm{~kg}\right.$ árv $\left.{ }^{-1}\right)$ e por unidade de área $\left(144,4\right.$ t.ha $\left.^{-1}\right)$, sendo composto principalmente por galhos $(69,3 \%)$, seguido das acículas $(17,9 \%)$, casca $(11,0 \%)$ e ponteira $(1,8 \%)$ por unidade de área. A correlação entre a massa dos componentes da biomassa por árvore e as variáveis independentes foi significativa e superior a 0,52 . A menor correlação foi observada entre estas e a quantidade ofertada de ponteiras. Os modelos de regressão selecionados para estimar a massa de biomassa em função das variáveis independentes tiveram $\mathrm{R}^{2}$ aju superiores a $83 \%$, baixos desvios padrões e coeficientes de variação.
\end{abstract}

Palavras-chave: Quantificação florestal; Uso múltiplo das florestas; Resíduos pós-colheita

\begin{abstract}
Along with the determination of how much of forest biomass is generated after the cultural interventions, it is possible to define areas that can be exploited. Thus, the objective of this work was to quantify and estimate the biomass supply of Pinus taeda L. available after cultural interventions. The experiment was carried out in populations in the cities of Paraná and Santa Catarina states, with ages of 3 years (first pruning), 5 years (second pruning), 7 years (third pruning), 11 years (first thinning), 19 years (second thinning), 23 and 33 years (harvesting). For each age, 10 trees were sampled and the components of the leaves, twigs, canopy and bark were quantified. After harvesting at 23 years old there was greater availability of individual

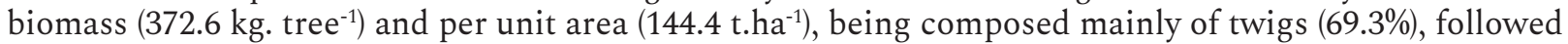
by leaves $(17.9 \%)$, bark (11.0\%) and canopy $(1.8 \%)$ per unit area. The correlation between the mass of the components of the biomass per tree and the independent variables was significant and higher to 0.52 . The lower correlation was observed between these and the mass of canopy. The regression models selected to estimate the mass of biomass from the independent variables had $\mathrm{R}^{2}$ adju higher than $83 \%$, low standard deviations and low coefficients of variation.
\end{abstract}

Keywords: Forest quantification; Multiple use of forests; Post-harvest residues

Engenheira Florestal, Drª ., Professora da Universidade Federal de Goiás, BR 364, km 195, 3800, CEP 75801-615, Jataí (GO), Brasil. cf.juliana@yahoo. com.br (ORCID: 0000-0002-0926-0082)

II Engenheira Florestal, Analista em infraestrutura de transportes, Departamento Nacional de Infraestrutura de Transportes (DNIT), Rua Aristóteles Soeiro Waltrick, 264, Bairro Frei Rogério, CEP 88508-050, Lages (SC), Brasil. thiellysf@hotmail.com (ORCID: 0000-0001-9295-8977)

III Engenheira Florestal, MSc., Doutoranda do Programa de Pós-Graduação em Ciência Florestal, Universidade Federal de Viçosa, Av. Purdue, s/nº, Câmpus Universitário, CEP 36570-900, Viçosa (MG), Brasil. eng-marcia@hotmail.com (ORCID: 0000-0001-5721-7807)

Iv Engenheira Florestal, Drª ., Professora da Universidade Federal do Paraná, Av. Pref. Lothário Meissner, 632, Jardim Botânico, CEP 80210-170, Curitiba (PR), Brasil. gbmunize@ufpr.br (ORCID: 0000-0003-4417-0178)

Engenheira Florestal, Drª -, Professora da Universidade do Estado de Santa Catarina, Av. Luiz de Camões, 2090, Bairro Conta Dinheiro, CEP 88520000, Lages (SC), Brasil. martha.brand@udesc.br (ORCID: 0000-0001-5438-2081)

vı Engenheira Florestal, Dra. em Ciência Florestal, Universidade Federal de Viçosa, Av. Purdue, s/nº , Câmpus Universitário, CEP 36570-900, Viçosa (MG), Brasil. thais_pfreitas@yahoo.com.br (ORCID: 0000-0002-5765-4908) 


\section{Introdução}

Em 2016, segundo dados da Indústria Brasileira de Árvores (INDÚSTRIA BRASILEIRA DE ÁRVORES, 2017), a área reflorestada com plantios de Pinus sp. no Brasil era de 1,6 milhão de hectares, com concentração especialmente no Sul do país, nos estados do Paraná, com $42 \%$ e em Santa Catarina, com $34 \%$. A extensa área plantada sugere um enorme potencial para exploração da biomassa disponível após as intervenções culturais dos povoamentos, especialmente por se tratar de reflorestamentos de uso múltiplo, que possuem um período de rotação longo, comumente superior a 16 anos. Os principais destinos da madeira em tora são para a produção de celulose, papel, madeira serrada, painéis de madeira reconstituída e geração de energia. Outras partes das árvores, como cascas, ramos, raízes, ponteiras, tocos, toretes e folhas são mantidos no campo após a colheita, considerados resíduos que são desperdiçados quanto ao aproveitamento da biomassa (BELLOTE et al., 1998; TOLOSANA et al., 2014; CASTRO et al., 2017).

No mesmo ano estima-se que foram gerados 47,8 milhões de toneladas de biomassa, oriundas da indústria de base florestal, que inclui casca, galhos, folhas, óleos, cavacos, serragem, aparas de papel, entre outros, passíveis de serem reaproveitados, especialmente para a geração de energia (INDÚSTRIA BRASILEIRA DE ÁRVORES, 2017). Segundo dados energéticos apresentados por Ortolan et al. (2011), este material teria um potencial energético equivalente ao de 9,8 milhões de toneladas de óleo ou 71,5 milhões de barris de petróleo.

O destino deste material como fonte de geração de energia se destaca no Brasil e no mundo, devido ao incentivo para o desenvolvimento de processos ecologicamente corretos, como as fontes de energia renováveis e ao aproveitamento dos subprodutos dos processos, gerando sistemas autossustentáveis. Segundo os dados apresentados pela Empresa de Pesquisa Energética (EPE) (2016), em 2015, a matriz energética brasileira foi composta por $41,2 \%$ de energias renováveis, entre as quais se destacaram a biomassa da cana $(16,9 \%)$, hidráulica (11,3\%) e lenha e carvão vegetal $(8,2 \%)$.

O setor florestal, diferente de outros setores econômicos é capaz de gerar a maior parte da energia consumida nos seus processos produtivos. Em 2016 foram gerados 67,5 milhões de gigajoules (GJ), equivalente à $69 \%$ do total consumido pelo setor. O licor negro, proveniente da produção da celulose, e a biomassa florestal representam $62,5 \%$ e $17,4 \%$ de toda energia térmica e elétrica produzida. Atividades específicas do setor florestal já se tornaram autossuficientes em energia, vendendo parte da energia gerada para as concessionárias de energia elétrica, como é o caso do setor de celulose (INDÚSTRIA BRASILEIRA DE ÁRVORES, 2017).

Mas para atender a esta demanda por energia é necessário buscar fontes contínuas de abastecimento de matéria-prima. Isso gera uma oportunidade para a condução dos povoamentos florestais com base em um sistema de manejo integrado da colheita com a pós-colheita, associados ao uso de novas tecnologias ou sistemas de trabalho (TOLOSANA et al., 2014). No entanto, a otimização e melhoria deste processo, visando ao tripé da sustentabilidade depende do desenvolvimento de modelos de gestão, tanto no Brasil, quanto no Mundo, acarretando em avanços tecnológicos e redução dos custos associados ao processo (HOBBS et al., 2016).

Entre as atividades culturais realizadas atualmente, as desramas visam à remoção de galhos da madeira, que estarão sem nós no momento da sua conversão em madeira serrada ou madeira laminada. Ao longo da condução dos povoamentos são realizados desbastes, definidos pelo controle do incremento em madeira pelas árvores e por fim, o corte raso, que estabelece o fim do ciclo do plantio. Os sistemas de corte das árvores mais utilizados no Brasil, para reflorestamentos com Pinus sp. são o sistema de toras longas (cutto-lenght), com o harvester e o forwarder para os desbastes e o sistema de árvores inteiras (full tree) com o feller-buncher, skidder e o processador para o corte raso (OLIVEIRA; PEREIRA, 2013).

A viabilidade de aproveitamento dos resíduos após a execução destes sistemas de colheita está condicionada a dois fatores principais: primeiramente, deve haver integração entre os sistemas de colheita da madeira e dos resíduos, que devem ser empilhados e mantidos limpos, sem contaminação com o solo, facilitando o transporte e manuseio. Este processo é facilitado em sistemas de colheita totalmente mecanizados. Em segundo, resíduos mais densos e com maiores dimensões aumentam a eficiência da atividade (SPINELLI, 2007; TOLOSANA, 2009). 
Para a correta tomada de decisão são necessários dados precisos da disponibilidade dos resíduos provenientes de cada intervenção, o que não ocorre para a biomassa florestal residual, diferentemente do controle de dados existente no setor de produção de carvão vegetal, energia hidráulica e energias não renováveis. Os dados existentes são insuficientes para estabelecer o planejamento da comercialização da biomassa. Para a melhoria deste controle e possibilidade de aumento da rentabilidade econômica, são necessários levantamentos contínuos e sucessivos da quantidade e qualidade da biomassa disponível nas florestas após as intervenções culturais (BRAND, 2000; SANQUETTA, 2002; BRAND, 2007).

Os principais métodos para quantificação da biomassa florestal podem ser diretos ou destrutivos, que envolvem a derrubada das árvores e a determinação direta da biomassa, e indiretos, relacionados à estimativa da biomassa, envolvendo relações alométricas, elaboradas a partir de estudos diretos realizados em campo. Os modelos gerados pelo método indireto podem ser aplicados tanto na estimativa de biomassa de locais específicos, quanto para aplicação em grandes áreas. O que difere entre os modelos gerados referese ao nível da amostragem. Quanto menos abrangente for a amostragem em termos de fatores de variação inclusos, mais aplicada a certas condições ele será, porém, não se recomenda o seu uso para a estimativa de biomassa de áreas extensas, com grande variabilidade (RIBEIRO et al., 2009). A estimativa da biomassa florestal tem sido feita pelos métodos indiretos, associando a sua produção às variáveis dendrométricas das plantas, como o diâmetro a altura do peito (DAP) e altura total, para a elaboração de modelos de regressão (BRIANEZI et al., 2013).

Deste modo objetivou-se quantificar o total de biomassa de Pinus taeda L. gerado após as intervenções de desrama, desbaste e corte raso e estimá-la com base em equações alométricas, correlacionando-as com as variáveis dendrométricas.

\section{Materiais e métodos}

O presente estudo foi realizado em plantios localizados em Mandirituba $\left(25^{\circ} 53^{\prime} 37^{\prime \prime} \mathrm{S}\right.$ e $49^{\circ} 17^{\prime} 36^{\prime \prime}$ W) e Rio Negro $\left(26^{\circ} 12^{\prime} 16^{\prime \prime} S\right.$ e $49^{\circ} 38^{\prime} 57^{\prime \prime}$ W), no Paraná e em Rio Negrinho $\left(26^{\circ} 15^{\prime} 16^{\prime \prime}\right.$ S e $\left.49^{\circ} 31^{\prime} 06^{\prime \prime} \mathrm{W}\right)$, Lages $\left(27^{\circ} 39^{\prime} 39^{\prime \prime}\right.$ S e $\left.49^{\circ} 59^{\prime} 11^{\prime \prime} \mathrm{W}\right)$ e Bocaina do Sul (27 44'40" S e $\left.49^{\circ} 56^{\prime} 40^{\prime \prime} \mathrm{W}\right)$, em Santa Catarina.

$\mathrm{Na}$ Tabela 1 encontram-se os dados do inventário florestal anual de 2011, para os povoamentos de Pinus taeda usados no estudo.

Tabela 1 - Dados do inventário florestal dos povoamentos de Pinus taeda utilizados no estudo.

Table 1 - Forest inventory data of stands of Pinus taeda used in study.

\begin{tabular}{cccccccc}
\hline Idade & Intervenção cultural & NA $($ árv.ha- & II $(\mathbf{\%})$ & DAP $(\mathbf{c m})$ & AT $(\mathbf{m})$ & AC $(\mathbf{m})$ & IS \\
\hline $\mathbf{3}^{\mathbf{1}}$ & Primeira desrama & 2000 & 100 & 10,92 & 6,6 & - & II \\
$\mathbf{5}^{\mathbf{1}}$ & Segunda desrama & 2000 & 100 & 14,5 & 9,2 & - & II \\
$\mathbf{7}^{\mathbf{1}}$ & Terceira desrama & 2000 & 55 & 16,47 & 12,1 & - & V \\
$\mathbf{1 1}^{\mathbf{2}}$ & Primeiro desbaste & 1358 & 45 & 20,85 & 16,4 & 10,7 & II \\
$\mathbf{1 9}^{\mathbf{3}}$ & Segundo desbaste & 741 & 50 & 30,32 & 24,7 & 20 & III \\
$\mathbf{2 3}^{\mathbf{4}}$ & Corte raso & 388 & 100 & 35,81 & 21,7 & 18,8 & II \\
$\mathbf{3 3}^{\mathbf{5}}$ & Corte raso & 523 & 100 & 35 & 33,5 & 29,7 & II \\
\hline
\end{tabular}

Fonte: Autor (2013)

Em que: $\mathrm{DAP}=$ diâmetro a altura do peito; $\mathrm{NA}$ = número de árvores; II = intensidade da intervenção; $\mathrm{AT}=$ altura total; $\mathrm{AC}=$ altura comercial; IS = índice de sítio. Municípios: ${ }^{1}$ Rio Negrinho, ${ }^{2}$ Rio Negro, ${ }^{3}$ Lages, ${ }^{4}$ Bocaina do Sul, ${ }^{5}$ Mandirituba. 
As desramas foram realizadas por um processo semimecanizado, com o auxílio de um podão, enquanto os sistemas de desbaste e corte raso foram totalmente mecanizados. $\mathrm{O}$ sistema de toras longas foi aplicado aos desbastes e o de árvores inteiras para os cortes rasos.

Para a primeira, segunda e terceira desrama todos os galhos e acículas até a altura de 1,7 $\mathrm{m} ; 3,3 \mathrm{~m}$ e 6,1 $\mathrm{m}$ do fuste das árvores, respectivamente, foram separados e pesados, enquanto para as árvores dos desbastes e cortes rasos, o procedimento foi realizado para todos os galhos, acículas e ponteira (parte do fuste com diâmetro inferior a oito centímetros).

Para cada povoamento selecionaram-se 10 árvores que tiveram um valor de DAP equivalente ao diâmetro da árvore de altura média do povoamento. A estimativa da massa de casca foi feita para as árvores sob intervenção de desbaste e corte raso, considerando a relação entre o seu volume $\left(\mathrm{m}^{3}\right)$ e sua massa específica básica (MEB) média $\left(\mathrm{kg} . \mathrm{m}^{-}{ }^{3}\right)$ (SANQUETTA, 2002). A MEB foi determinada segundo a norma ABNT NBR 11941 (2003). O volume foi estimado pela diferença entre o volume comercial do fuste com e sem casca, a partir da sua cubagem rigorosa, seguindo o método de Smalian, conforme realizado por Danielli et al. (2016). Para o volume comercial houve a relação entre a altura comercial (distância da base à ponta do fuste com diâmetro de oito centímetros) e os diâmetros da base, DAP, $25 \%, 50 \%$, $75 \%$ e $100 \%$ da altura comercial.

A oferta dos elementos quantificados por árvore ( $\left.\mathrm{kg} . a ́ r v^{-1}\right)$ e por área (t.ha $\left.{ }^{-1}\right)$, entre as diferentes intervenções aplicadas, passaram por análise estatística com o software Statistica, com aplicação do teste $\mathrm{F}$ e do teste de média de Tukey, ao nível de 5\% de probabilidade de erro.

A análise de correlação de Pearson (r) foi aplicada visando verificar a influência das variáveis independentes idade, DAP, altura total e altura comercial na oferta de biomassa total, de acículas, galhos, ponteiras e casca.

Modelos de regressão foram criados pelo procedimento stepwise, a fim de explicar a oferta em massa da biomassa total das árvores e entre os seus diferentes constituintes analisados em função das variáveis independentes. A escolha do modelo de regressão considerou o que obteve o maior coeficiente de determinação ajustado ( $\left.R^{2} a j u\right)$ e os menores erro padrão da estimativa (Syx) e coeficiente de variação (CV), entre todos os modelos gerados.

\section{Resultados e discussão}

O efeito das intervenções culturais (I), componentes da biomassa (C) e da interação entre eles ( $\mathrm{x} \times \mathrm{C}$ ) sobre a biomassa disponível foram significativos $(\mathrm{p}<0,05)$. Houve um acúmulo crescente de biomassa nas árvores, assim como a diferença de produção de biomassa entre os diferentes componentes ao longo dos anos, devido à distinção de intensidade das intervenções e ao aumento em idade das mesmas.

As maiores ofertas de biomassa em nível de árvore e por unidade de área ocorreu após o corte raso aos 23 anos (Tabela 2), assemelhando-se ao ofertado após o corte raso aos 33 anos. Na sequência, a quantidade de biomassa por árvore ofertada pelo segundo desbaste não diferiu do observado para o povoamento de 33 anos e foi superior ao proveniente do primeiro desbaste, enquanto para biomassa por área, a diferença foi significativa da idade de 33 anos e não significativa em relação ao primeiro desbaste.

Para as três idades de desrama, as ofertas totais de biomassa por árvore e por área não diferiram significativamente entre si. Apenas as ofertas por área aos três e sete anos não diferiram significativamente da oferta do primeiro desbaste. O galho foi o componente com maior oferta por árvore e por área, seguido da casca e acícula, que não diferiram entre si, e da ponteira. 


\section{Tabela 2 - Biomassa dos componentes residuais de Pinus taeda em diferentes idades por árvore $\left(\mathrm{kg}_{\text {.árv }}{ }^{-1}\right)$ e por área $\left(\mathbf{t} \cdot h \mathrm{a}^{-1}\right)$.}

Table 2 - Biomass of the residual components of Pinus taeda at different ages per tree (kg.tree $\left.{ }^{-1}\right)$ and per area $\left(\mathrm{t}_{\mathrm{h}} \mathrm{ha}^{-1}\right)$.

\begin{tabular}{|c|c|c|c|c|c|c|c|c|}
\hline \multicolumn{9}{|c|}{ Biomassa por árvore (kg.árv¹) } \\
\hline \multirow{2}{*}{ Componente } & \multicolumn{7}{|c|}{ Idade } & \multirow[b]{2}{*}{ Total } \\
\hline & 3 & 5 & 7 & 11 & 19 & 23 & 33 & \\
\hline Acícula & $2,5 \mathrm{Bd}$ & $0,6 \mathrm{Bd}$ & $2,5 \mathrm{Bd}$ & $18,6 \mathrm{Bc}$ & $29,7 \mathrm{Bbc}$ & $66,5 \mathrm{Ba}$ & $38,5 \mathrm{BCb}$ & $158,9 \mathrm{~B}$ \\
\hline Galho & $5,9 \mathrm{Ad}$ & $4,4 \mathrm{Ad}$ & 11,0 Acd & $43,8 \mathrm{Ac}$ & $128,0 \mathrm{Ab}$ & $258,4 \mathrm{Aa}$ & $154,4 \mathrm{Ab}$ & $605,9 \mathrm{~A}$ \\
\hline Ponteira & - & - & - & $15,8 \mathrm{Ba}$ & $13,8 \mathrm{Bab}$ & $6,6 \mathrm{Cc}$ & $10,7 \mathrm{Cbc}$ & $46,9 \mathrm{C}$ \\
\hline Casca & - & - & - & $11,0 \mathrm{Bb}$ & $34,2 \mathrm{Ba}$ & $41,1 \mathrm{Ba}$ & $40,2 \mathrm{Ba}$ & $126,5 B$ \\
\hline Total & $8,4 \mathrm{~d}$ & $5,0 \mathrm{~d}$ & $13,5 d$ & $89,2 \mathrm{c}$ & $205,7 \mathrm{~b}$ & $372,6 \mathrm{a}$ & $243,8 \mathrm{ab}$ & \\
\hline \multicolumn{9}{|c|}{ Biomassa por área (t.ha-1) } \\
\hline \multirow{2}{*}{ Componente } & \multicolumn{7}{|c|}{ Idade } & \\
\hline & 3 & 5 & 7 & 11 & 19 & 23 & 33 & Total \\
\hline Acícula & $5,0 \mathrm{ABc}$ & $1,2 \mathrm{Bc}$ & $3,3 \mathrm{Bc}$ & $11,2 \mathrm{Bb}$ & $11,0 \mathrm{Bb}$ & $25,8 \mathrm{Ba}$ & $20,1 \mathrm{BCa}$ & $77,6 \mathrm{~B}$ \\
\hline Galho & $11,8 \mathrm{Ac}$ & $8,9 \mathrm{Ac}$ & $15,2 \mathrm{Ac}$ & $26,2 \mathrm{Abc}$ & $47,4 \mathrm{Ab}$ & $100,2 \mathrm{Aa}$ & $80,8 \mathrm{Aa}$ & $290,5 \mathrm{~A}$ \\
\hline Ponteira & - & - & - & $9,5 \mathrm{Ba}$ & $5,1 \mathrm{Bb}$ & $2,6 \mathrm{Cc}$ & $5,6 \mathrm{Cb}$ & $22,8 \mathrm{C}$ \\
\hline Casca & - & - & - & $6,6 \mathrm{Bd}$ & $12,8 \mathrm{Bc}$ & $15,9 \mathrm{BCb}$ & $21,0 \mathrm{Ba}$ & $56,3 \mathrm{~B}$ \\
\hline Total & $16,8 \mathrm{~cd}$ & $10,1 \mathrm{~d}$ & $18,5 \mathrm{~cd}$ & $53,5 b c$ & $76,3 b$ & $144,5 \mathrm{a}$ & $127,5 \mathrm{a}$ & \\
\hline
\end{tabular}

Fonte: Autor (2013)

Médias seguidas pela mesma letra maiúscula na coluna e minúscula na linha não diferem significativamente pelo teste de Tukey, ao nível de 5\% de probabilidade

Após o processo de desrama, a quantidade de acículas e galhos gerados não diferiu significativamente entre as idades, mas houve diferença entre eles em cada idade, com oferta de galhos no mínimo 136\% superior à oferta de acículas, atingindo uma proporção de acículas:galhos de até 1:8,5 para biomassa por árvore e de 1:7,7 para biomassa por área. $\mathrm{O}$ aumento na oferta de biomassa por árvore entre os 11 e 19 anos foi de 131\%, enquanto para a biomassa por área, este aumento passou a ser de $43 \%$.

A partir dos dados da Tabela 1, as árvores aos 19 anos eram de maior porte do que aos 11 anos, resultado do crescimento natural e acúmulo de matéria-orgânica na árvore e da menor competição entre árvores, que foi intensificado especialmente após o desbaste anterior e que também resultou em maior geração de biomassa residual. Ao analisar a biomassa por área, observa-se pelos dados da Tabela 1, que foram retiradas 611 árvores no primeiro desbaste, enquanto no segundo desbaste, esta remoção foi de 370 árvores, o que possibilitou uma aproximação entre os valores ofertados após as duas intervenções.

Vieira, Schumacher e Bonacina (2011), ao quantificarem a biomassa proveniente de um povoamento de Pinus taeda sob o primeiro desbaste (nove anos), com remoção de 593 árv.ha $^{-1}$ (intensidade do desbaste de 35,6\%), observaram uma oferta de 5313,5 kg.ha-1 de galhos, seguido por $4007 \mathrm{~kg} \cdot \mathrm{ha}^{-1}$ de casca, 3612,1 kg.ha-1 de acículas e 945,3 kg.ha ${ }^{-1}$ de biomassa das ponteiras. Tais valores ficaram muito abaixo do observado neste estudo para o desbaste aos 11 anos, especialmente por este se tratar de um plantio mais velho. Entre outros 
fatores, a região, clima, aspectos nutricionais do solo, espécie e procedência interferem na atividade fisiológica das plantas e resultam em diferenças na assimilação dos nutrientes que constituirão a biomassa (SCHUMACHER; CALDEIRA, 2001).

No corte raso, ambos os plantios foram classificados com Índice de Sítio II (Tabela 1), o que os caracteriza com alta qualidade em relação ao crescimento, resultando em elevado incremento em biomassa. Apesar da semelhança quanto a esta classificação, observou-se que aos 23 anos, o menor número de árvores por hectare reduziu a competição entre as árvores e possibilitou uma maior ramificação e distribuição lateral dos galhos.

Além disso, o maior espaçamento entre as árvores possibilita maior crescimento em diâmetro, fornecendo madeira do fuste para fins mais nobres e com maior valor agregado. Com a maior proximidade entre as árvores, aos 33 anos, a quebra dos galhos das árvores remanescentes durante a realização dos desbastes foi mais intensa, assim como o aumento da própria desrama natural. O mesmo comportamento foi observado por Lupi et al. (2015) para plantios homogêneos de Populus sp. e Salix sp., ou seja, quanto maior o número de indivíduos por unidade de área, menor é o acúmulo de biomassa por indivíduo.

Para Santos et al. (2017), o espaçamento entre as árvores tem grande influência sobre crescimento arbóreo. Menores espaçamentos resultam em maior densidade populacional e, consequentemente, maior acúmulo de biomassa total do povoamento. No entanto, aumentam a competição entre os indivíduos por água, luz e nutrientes, reduzindo o seu crescimento. Entre os povoamentos sob corte raso, aos 23 anos foram retiradas 388 árv.ha ${ }^{-1}$, enquanto, aos 33 anos, foram cortadas 523 árv.ha $^{-1}$. A biomassa de fuste total para o povoamento de 33 anos tende a ser maior do que aos 23 , devido ao maior número de árvores por hectare. No entanto, a oferta de biomassa proveniente dos demais componentes das árvores e total por indivíduo tende a ser maior aos 23 anos, em virtude do maior espaçamento entre as árvores, resultando em maior acúmulo de fotoassimilados em toda a planta. Tal fato possibilitou uma oferta semelhante de biomassa por unidade de área entre os dois povoamentos.

Os dados de quantificação de biomassa proveniente de reflorestamentos de Pinus taeda do Rio Grande do Sul e Santa Catarina, apresentados por Schumacher et al. (2013) e Ferreira et al. (2016), respectivamente, são semelhantes aos encontrados no trabalho. Os povoamentos analisados tinham entre 10 e 27 anos de idade, sob as intervenções de desbaste ao corte raso. Algumas variações existentes devem ser levadas em conta devido às diferenças de espaçamento, técnicas de manejo utilizadas e condições de sítio, que podem ter influência sobre a produção e acúmulo de biomassa na planta.

Segundo dados apresentador por Castro et al. (2017), a oferta de galhos, casca, folhas e ponteiras, em plantios da variedade de eucalipto, resultado do cruzamento genético de Eucalyptus urophylla $\mathrm{x}$ Eucalyptus grandis, com 6,6 anos de idade foi bem inferior ao observado para os povoamentos de Pinus sp., com um total de $12,74 \mathrm{~kg}_{\text {árv }}{ }^{-1}$ e 17,03 t.ha ${ }^{-1}$. Tais valores foram semelhantes ao ofertado após a terceira desrama dos plantios deste estudo. No entanto, para a desrama, levou-se em conta apenas a oferta de galhos e folhas parciais da árvore. Isso demonstra o grande potencial de aproveitamento da biomassa proveniente da pós-colheita em povoamentos de Pinus taeda em comparação com plantio do gênero de Eucalyptus.

Os resultados observados por estes pesquisadores e enfatizado por Schumacher, Witschoreck e Calil (2011) e Tolosana et al. (2014), indicam que a disponibilidade de biomassa e a sua distribuição percentual nos diferentes componentes das árvores depende da espécie, idade, fertilidade do solo, densidade do plantio e sistema de manejo aplicado, entre outros, devendo ser avaliado para cada condição para se ter uma correta tomada de decisão. Para Schumacher, Witschoreck e Calil (2011), outro fator preponderante para esta forma de distribuição da biomassa se deve às fases nutricionais das plantas, que ocorrem ao longo do seu desenvolvimento.

Na primeira fase, que antecede ao fechamento das copas, há um intenso crescimento, com o acúmulo de fotoassimilados destinados à formação da copa e do sistema radicular. 
$\mathrm{Na}$ sequência, com o fechamento das copas, a segunda etapa envolve a concentração de nutrientes especialmente no tronco. Em virtude das condições dos povoamentos analisados e com base na maior oferta de biomassa de pós-colheita, o corte raso aos 23 anos pode ser mais vantajoso, devendo-se realizar uma análise econômica para definir o ganho real proveniente de todos os produtos extraídos do reflorestamento.

A remoção de resíduos após intervenções de desrama e desbaste podem afetar a ciclagem de nutrientes do solo. Segundo, Vieira, Schumacher e Bonacina (2011), ainda são necessários estudos que avaliem os efeitos da retirada dos resíduos do solo sobre a ciclagem de nutrientes.

A biomassa total e de seus componentes mostrou correlação positiva com a idade, DAP, altura total e altura comercial das árvores (Tabela 3). Quanto maior for a idade das árvores, maiores serão seus DAPs e alturas totais ou comerciais, refletindo em maior acúmulo de matéria orgânica na planta.

Tabela 3 - Coeficiente de correlação de Pearson (r).

Table 3 - Pearson correlation coefficient.

\begin{tabular}{lcccc}
\hline Biomassa $\left(\mathbf{k g . a ́ r v}^{\mathbf{1}}\right)$ & Idade $(\mathbf{a n o s})$ & DAP $(\mathbf{c m})$ & Altura total $(\mathbf{m})$ & Altura comercial $(\mathbf{m})$ \\
\hline Acícula & $0,73^{*}$ & $0,86^{*}$ & $0,66^{*}$ & $0,72^{*}$ \\
Galho & $0,74^{*}$ & $0,87^{*}$ & $0,66^{*}$ & $0,73^{*}$ \\
Ponteira & $0,52^{*}$ & $0,53^{*}$ & $0,57^{*}$ & $0,61^{*}$ \\
Casca & $0,91^{*}$ & $0,94^{*}$ & $0,88^{*}$ & $0,92^{*}$ \\
Total & $0,79^{*}$ & $0,91^{*}$ & $0,73^{*}$ & $0,79^{*}$ \\
\hline
\end{tabular}

Fonte: Autor (2013)

Em que: DAP = diâmetro a altura do peito $(\mathrm{cm}) ;{ }^{*}$ Correlação significativa ao nível de $5 \%$ de probabilidade de erro

A menor correlação foi observada entre a ponteira e as variáveis independentes, sendo que melhor se correlacionou com a altura comercial, seguido da altura total da árvore. O comprimento da ponteira é uma medida variável, relacionado ao diâmetro mínimo de corte para a produção das toras, o que é definido pelo setor de planejamento da empresa. Comumente, o diâmetro mínimo de corte é de oito a dez centímetros.

Para a casca, quanto maior o diâmetro do fuste, maior tende a ser a espessura de casca. A quantificação de casca foi baseada na altura comercial da árvore, que se refere ao montante de toras que será consumido.

Com base nas melhores correlações obtidas pela Tabela 3, foi feita a estimativa da oferta de biomassa, em massa, em função das variáveis dendrométricas, que foram o DAP e a altura total das árvores (Tabela 4), que são de fácil determinação no campo e têm sido tradicionalmente usadas em estudos de quantificação (LUPI et al., 2015). Castro et al. (2017) enfatizam em seu trabalho sobre quantificação de biomassa na produção de carvão vegetal, sobre a falta de equações alométricas específicas para estimar a disponibilidade de biomassa em povoamentos com espécies e de regiões distintos e facilitar a tomada de decisão, o que ainda requer o uso de amostragens destrutivas. 


\section{Tabela 4 - Estimativa da oferta dos componentes da biomassa de Pinus taeda com base nas variáveis dendrométricas dos povoamentos.}

Table 4 - Estimation of the supply of biomass components of Pinus taeda based on the dendrometric variables of populations.

\begin{tabular}{lcccc}
\hline Componente & Equação & $\mathbf{R}_{\text {Aiu }}^{2}$ & $\mathbf{S}_{\mathrm{vx}}$ & $\mathrm{CV}$ \\
\hline Acícula & $\mathrm{M}=-8,92469-0,90281^{*} \mathrm{DAP}+0,07502^{*} \mathrm{DAP}^{2}+1,69398^{*} \mathrm{H}-0,06201^{*} \mathrm{H}^{2}$ & 83,3 & 5,34 & 11 \\
Galho & $\mathrm{M}=-21,45621-7,02704^{*} \mathrm{DAP}+0,366971^{*} \mathrm{DAP}^{2}+9,90757^{\star} \mathrm{H}-0,29164^{*} \mathrm{H}^{2}$ & 87 & 19,14 & 16 \\
Ponteira & $\mathrm{M}=-14,70854-0,61709^{*} \mathrm{DAP}+3,20835^{*} \mathrm{H}-0,05356^{*} \mathrm{H}^{2}$ & 52,3 & 4,92 & 46,5 \\
Casca & $\mathrm{M}=57,18459-10,39604^{*} \mathrm{DAP}+0,54970^{*} \mathrm{DAP} \mathrm{P}^{2}-0,00760^{*} \mathrm{DAP} \mathrm{P}^{3}$ & 92,7 & 5,22 & 18,5 \\
$\begin{array}{l}\text { Biomassa } \\
\text { total }\end{array}$ & $\mathrm{M}=-69,94709+7,77544^{*} \mathrm{DAP}+0,24715^{*} \mathrm{DAP}^{2}-7,70961^{*} \mathrm{H}$ & 89,6 & 44,53 & 32,8 \\
\hline
\end{tabular}

Fonte: Autor (2013)

Em que: $\mathrm{M}=$ massa $\left(\mathrm{kg}_{\text {gárv }}{ }^{-1}\right) ; \mathrm{DAP}=$ diâmetro a altura do peito $(\mathrm{cm}) ; \mathrm{H}=$ altura total $(\mathrm{m}) ; \mathrm{R}^{2}{ }_{\mathrm{Aju}}=$ coeficiente de determinação ajustado; $S_{\mathrm{yx}}=$ erro padrão da estimativa $\left(\mathrm{kg}\right.$.árv $\left.{ }^{-1}\right) ; \mathrm{CV}=$ coeficiente de variação (\%)

O modelo quadrático foi o que melhor se ajustou à relação entre a massa de acículas e galhos com o DAP e altura total, assim como o preconizado por Giongo et al. (2011), em inventário de biomassa de Pinus elliottii, aos 23 anos de idade. Para a estimativa da massa de casca, uma equação de terceira ordem foi mais adequada. As equações selecionadas tiveram elevados $\mathrm{R}^{2}$ aju e baixos Syx (kg.árv-1) e CV (\%). Bellote e Silva (2004), por sua vez, utilizaram apenas o DAP como variável independente, para estimar a quantidade de biomassa aérea em povoamentos de Eucalyptus spp., obtendo resultados satisfatórios.

O modelo selecionado para estimar a massa das ponteiras teve um baixo $\mathrm{R}^{2}$ aju quando comparado às demais equações, além de um elevado CV. Com base nos dados de quantificação das ponteiras (Tabela 2), a sua oferta em massa não diferiu significativamente entre os plantios analisados, o que indica a ação de outros fatores que afetam a sua produção, mas que não foram considerados no ajuste das equações.

Como consequência, a variação observada para as ponteiras interferiu negativamente na estimativa da biomassa total, que considera o fator de variação de cada componente. Sendo assim, recomenda-se elaborar equações específicas para cada componente.

\section{Conclusões}

Em povoamentos com maior idade houve maior disponibilidade de biomassa total e por indivíduo.

A maior oferta de biomassa após o corte raso ocorreu para o povoamento com menos árvores remanescentes.

Após as operações de corte raso, houve um acúmulo de biomassa maior do que nas operações de desbaste e desrama.

Após a operação de corte raso houve a maior oferta de biomassa total e por indivíduo, tendo o galho como o material mais representativo, seguido da acícula, ponteira e casca. Fatores como a idade, a técnica de manejo utilizada e boa qualidade fisiológica, influenciados pelas características de sítio contribuíram para este resultado.

A quantidade de biomassa de acículas, galhos, casca e total por árvore teve elevada correlação com as variáveis dendrométricas de DAP e altura total das árvores. 


\section{Agradecimentos}

À empresa Modo Battistella Reflorestamento S.A. (MOBASA), pelo fornecimento do material utilizado no estudo.

À Universidade Federal do Paraná (UFPR) e à Universidade do Estado de Santa Catarina (UDESC).

À Coordenação de Aperfeiçoamento Pessoal de Nível Superior (CAPES), pela concessão de bolsa de pesquisa.

\section{Referências}

ASSOCIAÇÃO BRASILEIRA DE NORMAS TÉCNICAS. NBR 11941: Madeira - Determinação da densidade básica. Rio de Janeiro, 2003.

BELLOTE, A. F. J. et al. Resíduos da indústria de celulose em plantios florestais. Boletim de Pesquisa Florestal, Colombo, n. 37, p. 99-106, 1998.

BELLOTE, A. F. J.; SILVA, H. D. Sampling techniques and nutritional evaluations in eucalypt plantations. In: GONÇALVES, J. L. M.; BENEDETTI, V. (Ed.). Forest nutrition and fertilization. Piracicaba: IPEF, 2004. p. 113-139.

BRAND, M. A. Qualidade da biomassa florestal para o uso na geração de energia em função da estocagem. 2007. 169 f. Tese (Doutorado em Ciências Florestais) - Universidade Federal do Paraná, Curitiba, 2007.

BRAND, M. A. Rendimento do processo produtivo e energético da matéria-prima de uma indústria de base florestal. 2000. 180 f. Dissertação (Mestrado em Engenharia Florestal) Universidade Federal do Paraná, Curitiba, 2000.

BRIANEZI, D. et al. Equações alométricas para estimativa de carbono em árvores de uma área urbana em Viçosa-MG. Revista Árvore, Viçosa, MG, v. 37, n. 6, p. 1037-1081, 2013.

CASTRO, A. F. N. M. et al. Quantification of forestry and carbonization waste. Renewable Energy, Oxford, v. 103, p. 432-438, 2017.

DANIELLI, F. E. et al. Modelagem do rendimento no desdobro de toras de Manilkara spp. (Sapotaceae) em serraria do estado de Roraima, Brasil. Scientia Forestalis, Piracicaba, v. 44, n. 111, p. 641-651, 2016.

EMPRESA DE PESQUISA ENERGÉTICA. Balanço energético nacional 2016: ano base 2015. Rio de Janeiro: EPE, 2016. 296 p.

FERREIRA, J. C. et al. Qualificação da biomassa em povoamentos florestais de Pinus taeda. Floresta, Curitiba, v. 46, n. 2, p. 269-276, 2016.

GIONGO, M. et al. Inventário de biomassa em um plantio de Pinus elliottii Engelm. aos 23 anos de idade. Journal of Biotechnology and Biodivesity, Tocantins, v. 2, n. 3, p. 81-86, ago. 2011.

HOBBS, T. J. et al. Models of reforestation productivity and carbon sequestration for land use and climate change adaptation planning in South Australia. Journal of Environmental Management, London, v. 181, p. 279-288, 2016.

INDÚSTRIA BRASILEIRA DE ÁRVORES. Relatório anual 2017. Brasília: IBÁ, 2017. 80 p.

LUPI, C. et al. Evaluating sampling designs and deriving biomass equations for Young plantations of poplar and willow clones. Biomass and Bioenergy, Oxford, v. 83, p. 196-2015, 2015.

OLIVEIRA, F. M.; PEREIRA, A. L. S. Comparação da produtividade entre equipamentos em dois sistemas de colheita de madeira de eucalipto. Revista Científica Eletrônica de Engenharia Florestal, Garça, v. 22, n. 1, p. 30-40, 2013. 
ORTOLAN, C. et al. Aproveitamento da biomassa residual de colheita florestal. 2011. Disponível em: <http://www.ciflorestas.com.br/arquivos/doc_aproveitamento_florestal_11596. pdf $>$. Acesso em: 14 out. 2015.

RIBEIRO, S. C. et al. Quantificação de biomassa e estimativa de estoque de carbono em uma floresta madura no município de Viçosa, Minas Gerais. Revista Árvore, Viçosa, MG, v. 33, n. 5, p. 917-926, 2009.

SANQUETTA, C. R. Métodos de determinação de biomassa florestal. In: SANQUETTA, C. R. et al. (Ed.). As florestas e o carbono. [s. l.: s. n.], 2002. p. 119-140.

SANTOS, M. D. et al. Avaliação da produção de biomassa do fuste de um clone híbrido de eucalipto sob diferentes espaçamentos. Ciência Florestal, Santa Maria, v. 27, n. 1, p. 31-45, 2017.

SCHUMACHER, M. V.; CALDEIRA, M. V. W. Estimativa da biomassa e do conteúdo de nutrientes de um povoamento de Eucalyptus globulus (Labillardiere) sub-espécie maidenii. Ciência Florestal, Santa Maria, v. 11, n. 1, p. 45-53, 2001.

SCHUMACHER, M. V. et al. Biomassa e nutrientes no corte raso de um povoamento de Pinus taeda L. de 27 anos de idade em Cambará do Sul - RS. Ciência Florestal, Santa Maria, v. 23, n. 2, p. 321-332, 2013.

SCHUMACHER, M. V.; WITSCHORECK, R.; CALIL, F. N. Biomassa em povoamentos de Eucalyptus spp. de pequenas propriedades rurais em Vera Cruz, RS. Ciência Florestal, Santa Maria, v. 21, n. 1, p. 178,22, 2011.

SPINELLI, R. Biomass, LAGs and the transnational project. In: GAIO, G.; DA VAL, J.; CARRARA, L. (Ed.). Guidelines for the development of a forest chips supply chain model. Italy: CNR; IVALSA, 2007. p. 14-43.

TOLOSANA, E. Manual tecnico para el aprovechamiento y elaboracion de biomasa forestal. Madrid: Mundi-Prensa, 2009. 348 p.

TOLOSANA, E. et al. Residual biomass recovery from fully-mechanized delayed thinnings on Spanish Pinus spp. plantations. Biomass and Bioenergy, Oxford, v. 71, p. 98-105, 2014.

VIEIRA, M.; SCHUMACHER, M. V.; BONACINA, D. M. Biomassa e nutrientes removidos no primeiro desbaste de um povoamento de Pinus taeda L. em Cambará do Sul, RS. Revista Árvore, Viçosa, MG, v. 35, n. 3, p. 371-379, 2011. 